\title{
Development of an Ultrasonic Motor That Uses an Inchworm Shaped Deformation of a Metallic Plate
}

\author{
Akihiro Naganawa', Kazumi Komatsu', Hisashi Ito² \\ ${ }^{1}$ Department of Systems Design Engineering, Graduate School of Engineering Science, Akita University, Akita City, Japan \\ ${ }^{2}$ Best Corporation, Kitakami City, Japan \\ Email: naganawa@gipc.akita-u.ac.jp
}

How to cite this paper: Naganawa, A., Komatsu, K. and Ito, H. (2016) Development of an Ultrasonic Motor That Uses an Inchworm Shaped Deformation of a Metallic Plate. World Journal of Engineering and Techno$\log$, 4, 100-106.

http://dx.doi.org/10.4236/wjet.2016.43D013

Received: July 19, 2016

Accepted: October 13, 2016

Published: October 20, 2016

\begin{abstract}
At the present time, ultrasonic motors have been developed for a variety of purposes such as linear motion drives and rotational drives. The elaboration of an ultrasonic motor is time-consuming, because it is developed adapting on its application. In this study, a new ultrasonic motor structure that combines a piezoelectric element and a metallic plate is elaborated. The driving principle of this motor is that the metal plate is bent to an inchworm shape and rotates the rotor when the piezoelectric element is stretched. The objective of this study is to verify the functioning of the new motor experimentally.
\end{abstract}

\section{Keywords}

Ultrasonic Motor, Piezoelectric Element, Metallic Plate, Inchworm-Shaped Deformation

\section{Introduction}

Ultrasonic motors are actuators that primarily use piezoelectric elements to convert the electrical energy into a mechanical energy. The ultrasonic motor usually has a stator (a slider is used, when the object is under linear motion) that vibrates at an ultrasonic speed and uses friction between the stator and rotor. The first applied in practice ultrasonic motor is a rotational traveling-type ultrasonic motor made in Japan in 1986. Ultrasonic motors have the following features [1] [2]:

- The ultrasonic motor can produce high torque at low speed, when it is compared with a normal electromagnetic DC motor, which has high efficiency but low torque at high speed.

- The torque produced per unit weight is higher than that of the electromagnetic motor, because of the frictional driving. 
- Since a large torque is obtained, there is no need of gears, and the direct drive is possible.

- The position can be maintained due the friction force between the contact surfaces, when the electrical power source is not applied.

Because of these features, motors of various drive principles are developed. As examples such motors are traveling-type motors [3] [4], smooth impact drive mechanism (SIDM) type motors [5] [6], and others [7] [8]. Thus various types of motors are developed. However, most of them are difficult to be downsized.

The purpose of this study is to design and fabricate an ultrasonic motor that combines a piezoelectric element with a metallic plate. The performance of the motor is verifies experimentally. The features of the new motor are as follows:

- The structure of the ultrasonic motor is quite simple.

- The metallic plate can expand the small displacement of the piezoelectric element.

- The motor can be easily downsized because of the introduction of an expanded mechanism using the metallic plate.

\section{Driving Principle of the Motor}

Figure 1 shows the driving principle of the ultrasonic motor. The structure of the stator includes a piezoelectric element and a metallic plate in series. If we input the driving signal into the piezoelectric element, the voltage causes the piezoelectric element stretching in horizontal direction. This extension pushes the the metallic plate, which causes bending of the metallic plate in vertical direction. By the ratio between the displacement of the horizontal direction and the displacement of the vertical direction, the extended displacement can be obtained.

Figure 2 shows the driving signal: (a) is a driving wave by the anticlockwise rotation, and (b) is a driving wave by the clockwise rotation. The signal is a sawtooth wave and the ratio of the voltage up and down is 1:8:1, as it is shown in Figure 2. For example,

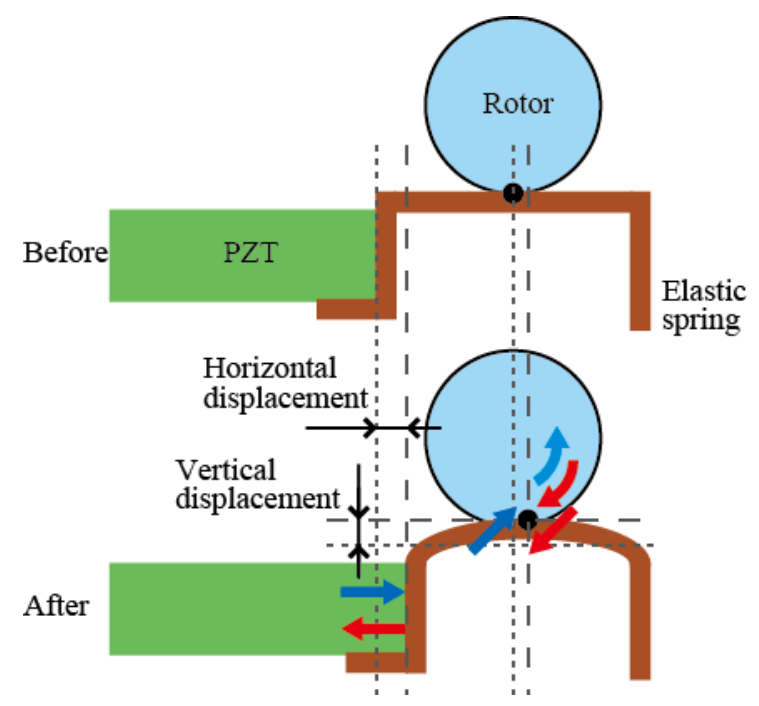

Figure 1. Driving principle of the ultrasonic motor. 


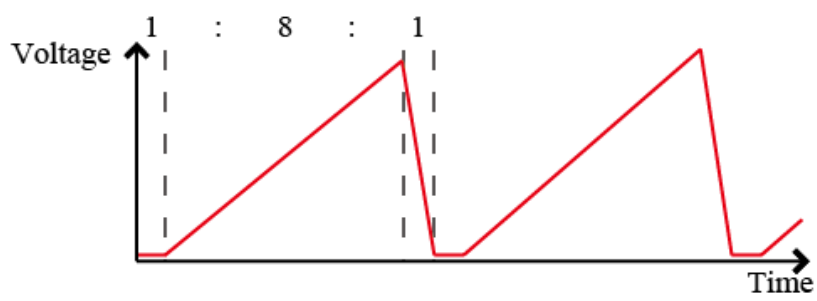

(a) Anticlockwise rotation

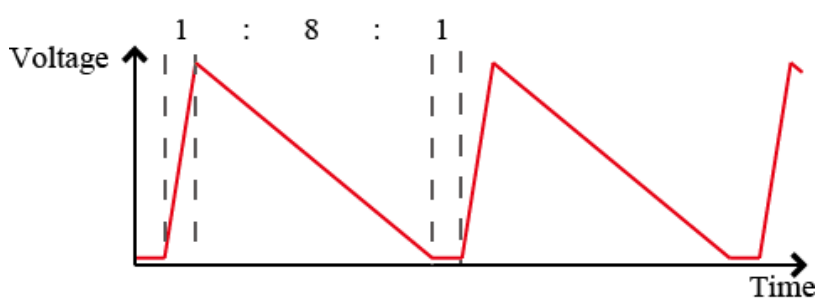

(b) Clockwise rotation

Figure 2. Driving wave.

wave (a) means a slow stretch and rapid shortening when the rotor rotates in the anticlockwise direction. On the other hand, to cause the rotor to rotate in the clockwise direction, the wave (b) is applied.

\section{Characteristics of the Stator}

Figure 3 shows the stator of the new ultrasonic motor. The height, length and width of the stator are $2 \mathrm{~mm}, 10 \mathrm{~mm}$ and $3 \mathrm{~mm}$, respectively. The piezoelectric element is a multilayer-type element which is made by NEC/Tokin Corp. in Japan (type AE0203D04F, length $5 \mathrm{~mm}$, maximum displacement $4.6 \pm 1.5 \mu \mathrm{m} / 150 \mathrm{~V}$, generated force $200 \mathrm{~N}$ ). The material of the metallic plate is phosphor bronze with a board thickness of $2 \mathrm{~mm}$.

Figure 4 shows the result of finite element method (FEM) analysis when the thickness of piezoelectric elements is increased by $5.0 \mu \mathrm{m}$. From this figure, it can be seen that the metallic plate is deformed into an inchworm shape with a maximum displacement of $6.144 \mu \mathrm{m}$. Therefore, the ratio of the displacement expansion is 1.23 times bigger than the displacement of the piezoelectric element.

Then the displacement and frequency characteristics of the stator are measured.

Figure 5 shows the measurement results of the displacement characteristic when the metallic plate is pushed by the piezoelectric element. It is generated a $1 \mathrm{~Hz}$ trapezoidal wave from a function generator and it is applied as the driving signal by its amplifying with an amplifier. The horizontal and vertical displacement are detected by a laser sensor, and the data are recorded with an oscilloscope. When the voltage of $140 \mathrm{~V}_{\mathrm{PP}}$ is applied, the maximum displacement will be $4.303 \mu \mathrm{m}$ in the horizontal direction and $4.771 \mu \mathrm{m}$ in the vertical direction. Therefore, the ratio of the displacement expansion is 1.11 times, and the error for the FEM analysis is $10 \%$. The reasons for the error between the FEM analysis and the experiment are manufacturing error, the influence of the adhesion materials, and other factors. 


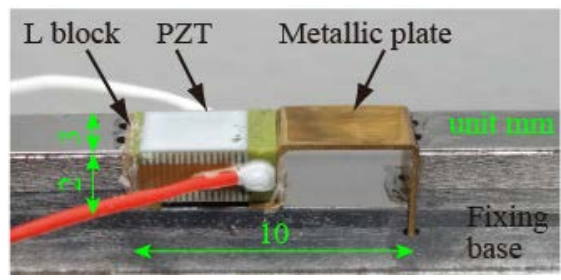

Figure 3. Stator of the new ultrasonic motor.

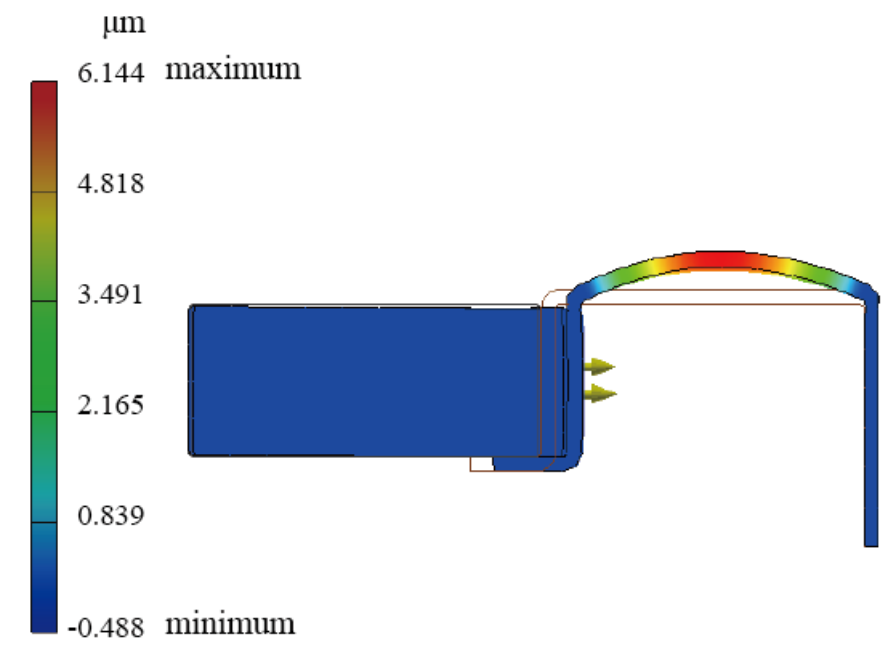

Figure 4. Result of FEM analysis.

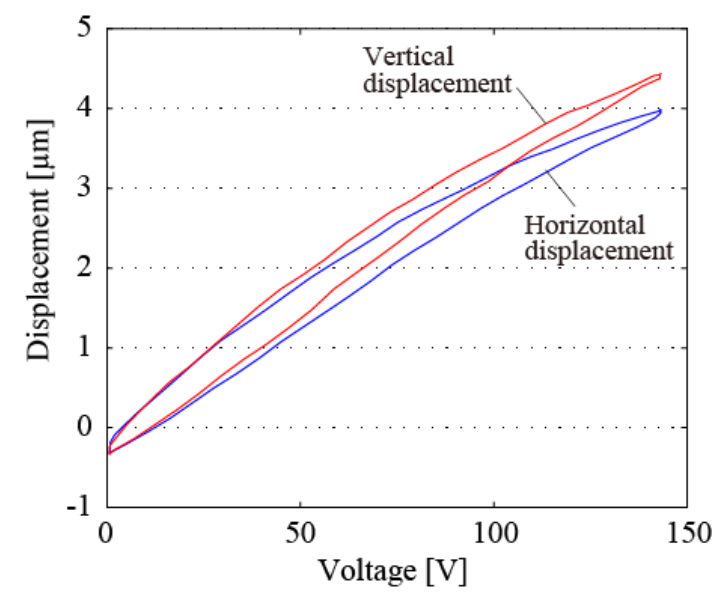

Figure 5. Measurement results of the displacement comparison with response for the stator.

Figure 6 shows the measurement result of the frequency characteristic. $75 \mathrm{~V}$ offset voltage is applied to the piezoelectric element. The $33.4 \mathrm{kHz}$ resonance frequency is shown in this figure.

\section{Performance of the Motor}

Figure 7 shows the experimental equipment for the rotational property. The stator is commented in Section 3. A rotor is used to verify the rotation characteristics of the sta- 


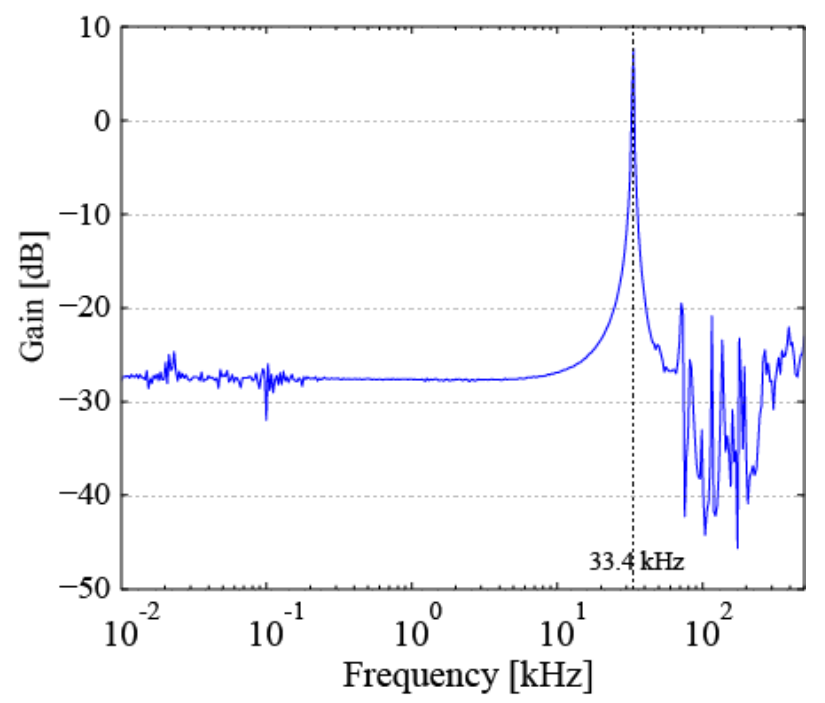

Figure 6. Measurement result of the frequency response for the stator.

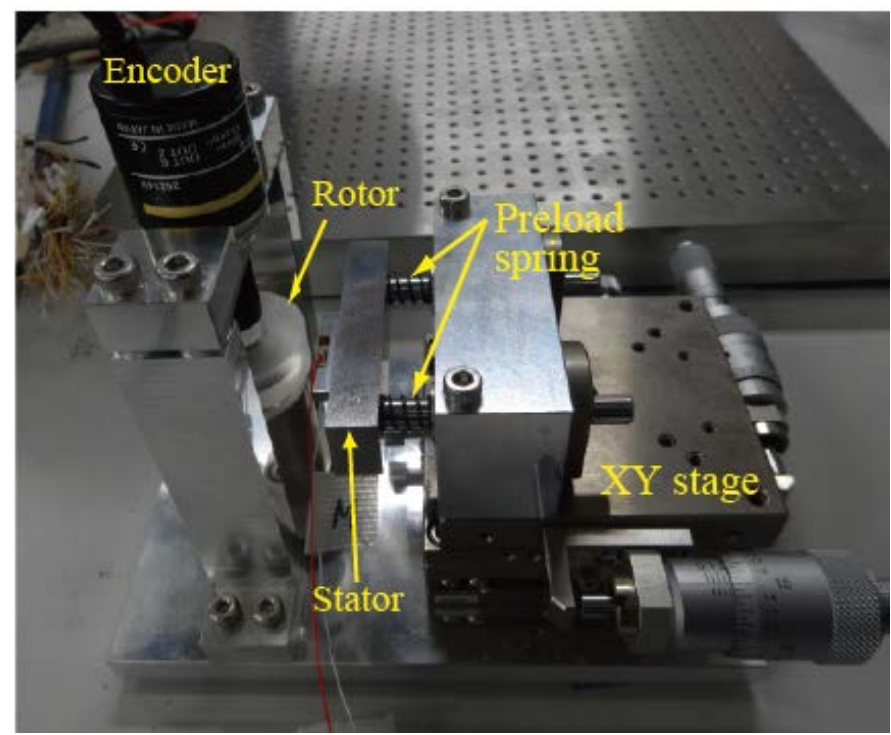

Figure 7. Experimental equipment for the rotational property.

tor. The rotor is made from acrylic and its size is $30 \mathrm{~mm}$ in diameter. The stator is attached to the side of an XY stage and verified the rotary drive while the position of the stator is adjusted. A preload, which uses two springs with a spring constant of $2 \mathrm{~N} / \mathrm{mm}$, is applied to the stator. An experiment with the driving signals is shown in Figure 2. The sawtooth waves have a maximum amplitude of $100 \mathrm{~V}$. The rotational speed of the rotor is measured using a rotary encoder.

Figure 8 shows the experimental results of the rotational property. The horizontal axis illustrates the preload applied to the stator and the driving frequency applied to the piezoelectric element. The vertical axis shows the rotational speed measured by rotary encoder. From the results, it can be seen that in the dead zone, the motor does not rotate with the driving frequency, and the driving performance varies with the preload. 


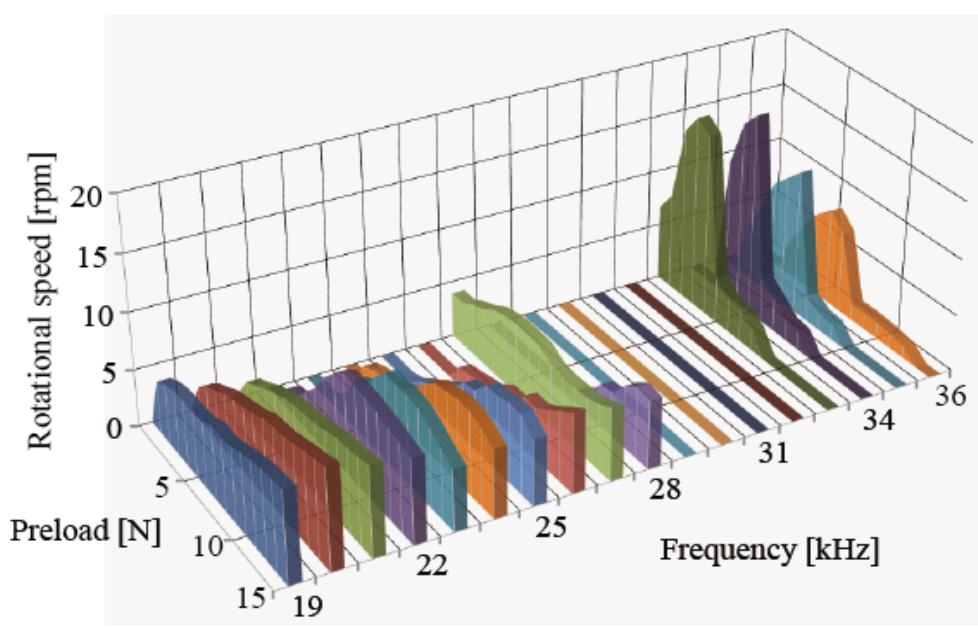

Figure 8. Results of the rotational property (anticlockwise direction).

The maximum rotation speed by the anticlockwise direction is $17.8 \mathrm{rpm}$ when the condition is $34.0 \mathrm{kHz}$ driving frequency and $6 \mathrm{~N}$ preload.

On the other hand, the maximum speed for the clockwise direction is $9.62 \mathrm{rpm}$ when the condition is $18.0 \mathrm{kHz}$ driving condition and $9 \mathrm{~N}$ preload.

\section{Conclusion}

In the study, a new ultrasonic motor structure that utilizes an inchworm-shaped deformation on a metallic plate is offered. The structure consists of a multilayer piezoelectric element and a metallic plate in series. The principle of the new motor is to use the metallic plate in order to enlarge the displacement of the piezoelectric element, and the deformation of the metallic plate can move the rotor (or slider). A rotation speed of the rotor is approximately determined around $10-18 \mathrm{rpm}$, when the experiments for observing the rotary drive characteristics are realized. In the future work the performance of the motor will enhance by redesigning the stator.

\section{Acknowledgements}

This work was supported by JSPS KAKENHI Grant Number JP15K05885. We also thank Mr. Yuki Abe, who performed the experiments.

\section{References}

[1] Sashida, T. and Kenji, T. (1993) An Introduction to Ultrasonic Motor. Oxford University Press, Oxford.

[2] Maeno, T. (2003) Ultrasonic Motors. Journal of the Robotics Society of Japan, 21, 10-14. (In Japanese) http://dx.doi.org/10.7210/jrsj.21.10

[3] Chen, T.-C., Yu, C.-H. and Tsai, M.-C. (2008) A New Driver Based on Dual-Mode Frequency and Phase Control for Traveling-Wave Type Ultrasonic Motor. Energy Conversion and Management, 49, 2767-2775. http://dx.doi.org/10.1016/j.enconman.2008.03.023

[4] Shi, Y.L. and Zhao, C.S. (2011) A New Standing-Wave-Type Linear Ultrasonic Motor Based on In-Plane Modes. Ultrasonic, 51, 397-404. http://dx.doi.org/10.1016/j.ultras.2010.11.006 
[5] Okamoto, Y., Yoshida, R. and Sueyoshi, H. (2004) The Development of a Smooth Impact Drive Mechanism (SIDM) Using a Piezoelectric Element. Konica Minolta Technology Report, 1, 23-26. (In Japanese)

[6] Nishimura, T., Hosaka, H. and Morita, T. (2012) Resonant-Type Smooth Impact Drive Mechanism (SIDM) Actuator Using a Bolt-Clamped Langevin Transducer. Ultrasonic, 52, 75-80.

[7] Pan, Q.S., He, L.G., Pan, C.L., Xiao, G.J. and Feng, Z.H. (2014) Resonant-Type Inertia Linear Motor Based on the Harmonic Vibration Synthesis of Piezoelectric Bending Actuator. Sensors and Actuators A: Physical, 209, 169-174. http://dx.doi.org/10.1016/j.sna.2014.01.027

[8] Hou, X.Y., Lee, H.P., Jin, O.C. and Piang, L.S. (2013) Development and Numerical Characterization of a New Standing Wave Ultrasonic Motor Operating in the $30-40 \mathrm{kHz}$ Frequency Range. Ultrasonic, 53, 928-934. http://dx.doi.org/10.1016/j.ultras.2012.10.016

Submit or recommend next manuscript to SCIRP and we will provide best service for you:

Accepting pre-submission inquiries through Email, Facebook, LinkedIn, Twitter, etc. A wide selection of journals (inclusive of 9 subjects, more than 200 journals)

Providing 24-hour high-quality service

User-friendly online submission system

Fair and swift peer-review system

Efficient typesetting and proofreading procedure

Display of the result of downloads and visits, as well as the number of cited articles

Maximum dissemination of your research work

Submit your manuscript at: http://papersubmission.scirp.org/

Or contact wjet@scirp.org 